\title{
Donor Retested Negative
}

National Cancer Institute

\section{Source}

National Cancer Institute. Donor Retested Negative. NCI Thesaurus. Code C133332.

A test result of negative infectious disease markers at subsequent testing of blood products that have been stored for a minimum of 112 days. 